$\infty$

0

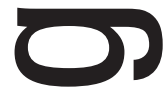

-

ת

1

$\longrightarrow$ 



\title{
COMPARTIMENTAÇÃO PEDOLÓGICA DA BACIA DO RIO DOS BOIS, MUNICÍPIOS DE CEZARINA, VARJÃO, GUAPÓ E PALMEIRAS DE GOIÁS (G0), E SUA RELAÇÃO COM A SUSCETIBILIDADE E RISCO À EROSÃO LAMINAR. ${ }^{1}$
}

\author{
COMPARTIMENTS PEDOLOGICAL THE RIVER BASIN OF STEERS, MUNICIPALITIES CECARINA, \\ VARJÃO, GUAPÓ E PALMEIRAS DE GOIÁS (GO) AND ITS RELATIONSHIP THE SUSCEPTIBILITY TO \\ EROSION RISK AND LAMINAR
}

\author{
Fernando Pereira dos Santos - CEPAE/UFG \\ fsantos@cepae.ufg.br \\ Maximiliano Bayer - IESA/UFG \\ maxibayer@yahoo.com.ar \\ Thiago Morato de Carvalho - LABOGEF/UFG \\ tmorato@infonet.com.br
}

\section{Resumo}

0 presente trabalho apresenta uma análise ambiental e dos conflitos de uso dos solos da bacia do rio dos Bois, a partir da compartimentação morfopedológica, da delimitação dos graus de suscetibilidade à erosão laminar e do uso do solo, como subsídio ao planejamento do uso do solo. Foi realizado com base em correlação espacial utilizando técnicas de SIG, com ênfase na erodibilidade dos solos. Como resultados foram observados conflitos de uso e ocupação do solo, além de áreas onde é necessária a intervenção no sentido de prevenir as erosões laminares.

Palavras-chave: compartimentação morfopedológica, Suscetibilidade à erosão laminar, conflitos de uso

\begin{abstract}
The aim of this paper is to present an environmental analysis related to the risks of land use in Bois river basin, based on morphopedological compartmentation and mapping the soil erosion susceptibility, to give a subsidy to soil management. The proceeding based on SIG methodology. The results can be show the risks at soil ocupation, besides areas with necessary intervation to prevent laminar erosions.
\end{abstract}

Key-words: morphopedologic compartments, laminar erosion susceptibility, risks of soil uselntrodução

\begin{tabular}{|l|c|c|c|c|c|c|}
\hline Boletim Goiano de Geografia & Goiânia - Goiás - Brasil & v. 28 & n. 2 & p. 103-124 & jul. / dez. & 2008 \\
\hline
\end{tabular}





\section{Introdução}

No estudo dos processos erosivos, os condicionantes relativos ao meio físico (rochas, relevo, solos, cobertura vegetal, clima) assumem papel preponderante não só para o seu entendimento, como também para a delimitação de áreas que apresentam suscetibilidades e riscos variáveis à medida que elas variam no resultado da combinação desses condicionantes. As rochas, por exemplo, fornecem material de origem para os solos, os quais vão variar em função da natureza e estrutura litológicas. Em geral, há correspondência entre solos e rochas (ou sedimentos recentes, inconsolidados) e relevos associados (Salomão, 1999).

As formas de relevo podem ser consideradas fatores que exercem grande influência sobre as condições locais nos distintos setores topográficos de uma dada área; a inclinação das vertentes, a rugosidade do terreno ou o entalhamento dos canais caracterizam, dentre outros aspectos, o grau e a potencialidade de uso das terras, juntamente com os solos. As variadas formas de representar as feições do relevo, tais como cartas de declividade, mapas hipsométricos e perfis topográficos, possibilitam delimitar setores com relevos de características similares e avaliar as condições hidropedológicas operantes em cada um, sobretudo a relação entre escoamento superficial das águas pluviais e as taxas de infiltração. Assim, relevos planos e contínuos tendem a apresentar solos profundos e fortemente intemperizados, dando-se o oposto em relevos movimentados (Lepsch, 2002).

A topografia envolve, sobretudo, a declividade do terreno e o comprimento de rampa, fatores que têm papel bastante importante no processo erosivo. O grau do declive influencia tanto na velocidade quanto no volume da enxurrada. Em baixas declividades, a velocidade da enxurrada é pequena, tendo o solo mais tempo para absorvê-la, enquanto que, numa declividade maior, a velocidade da enxurrada será maior e maior será também o seu volume e, em conseqüência, maior será a erosão. O mesmo se dá em relação ao comprimento do lançante, sendo que, quanto maior o comprimento, maior será a velocidade da enxurrada e maior o seu volume (Salomão, 1999).

Há dois grandes tipos de erosão, a laminar, produto do escoamento superficial difuso das águas pluviais precipitadas sobre o solo, e a linear, produto do escoamento superficial concentrado (em linhas e eixos) das águas pluviais caídas no solo, promovendo a formação de sulcos e ravinas. O presente trabalho aborda a erosão laminar, onde filetes ou lâminas d'água difusos serpenteiam sobre os solos sem formar canais, mas são capazes de remover quantidades consideráveis de solo, deixando raízes visíveis, cercas suspensas, assoreamento das zonas mais baixas, redução na produtividade,e outros. 
A definição e delimitação de um setor, compartimento ou zona, varia de acordo com as características físicas da área estudada e da escala do estudo. De forma geral, utiliza-se atributos do relevo e os solos como fatores determinantes para traçar os limites de áreas homogêneas. Castro e Salomão (2000) denominam essas áreas homogêneas assim delimitadas, em médias e grandes escalas de compartimentos morfopedológicos.

O objetivo do presente trabalho é apresentar a compartimentação morfopedológica da bacia hidrográfica do rio dos Bois, situada no centro sulgoiano, caracterizando cada compartimento, em função dos seus atributos geológicos, geomorfológicos e pedológicos, e suas relações com o uso atual, de modo a avaliar a suscetibilidade erosiva laminar e os graus de conflito de uso e o potencial (risco) erosivo.

\section{Localização da área de estudo}

A bacia hidrográfica do rio dos Bois foi selecionada devido à ocupação e ao uso das terras terem atingido sua plenitude. Está localizada a $\sim 50 \mathrm{~km}$ da cidade de Goiânia e apresenta um terreno irregular, com $600 \mathrm{~km}^{2}$ de área, situando-se, em sua maior parte, no município de Cezarina e em parte dos municípios de Guapó, Varjão e Palmeiras de Goiás (Figura 1).

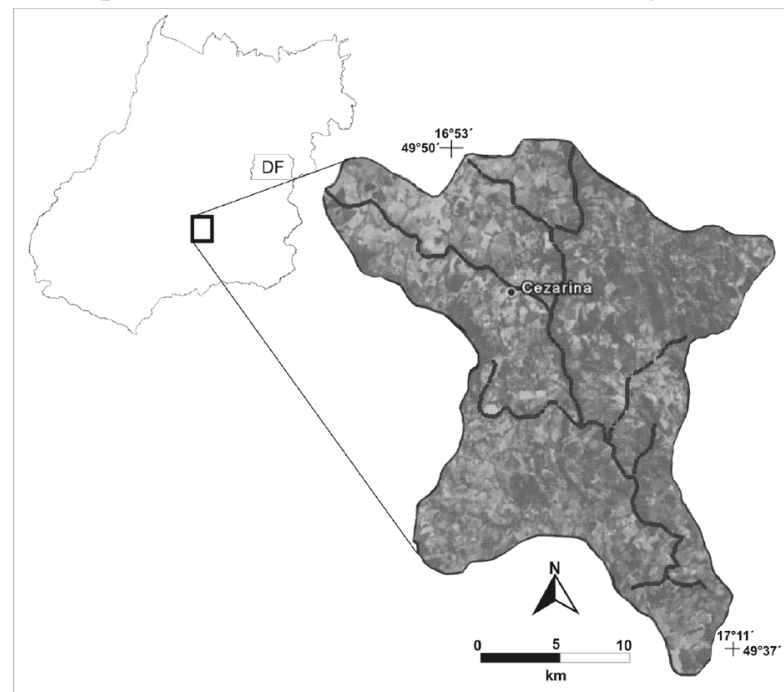

Figura 1. Localização da bacia hidrográfica do rio dos Bois, GO delimitada sobre imagem CBERS. 


\section{Materiais e métodos}

O estudo foi desenvolvido em três etapas:

\section{$1^{\text {a }}$. Compartimentação Morfopedológica}

Foi elaborada com base nas informações de geomorfologia, solos e geologia, com base em imagens de radar por interferometria (radar interferométrico nas bandas $\mathrm{C} / \mathrm{X}$ ) as quais foram geradas en produtos de MDT - Modelo Digital do Terreno derivados da Shuttle Radar Topography Mission (SRTM), e em produtos cartográficos temáticos do Sistema de Informações Estatísticas e Geográficas (SIEG) do Estado de Goiás, como geologia, geomorfologia e solos, na escala de 1:250.000.

Os produtos de hipsometria e declividade foram elaborados a partir do MDT (SRTM) com uso do programa ENVI 4.2, que permite extrair informações topográficas para escalas de até 1:100.000 (Carvalho, 2003 a,b; Carvalho e Latrubesse 2004; Latrubesse e Carvalho ,2006). As classes de declividade foram extraídas em graus, sendo de 5 em 5 graus, e a hipsometria, ou seja, o fatiamento do relevo foi de 50 em 50 metros. Essas classes foram utilizadas, pois melhor expressaram as características do relevo da bacia. Os perfis topográficos foram elaborados no programa ENVI 4.2, a partir dos produtos da SRTM, os quais serviram para a caracterização do relevo em cada compartimento morfopedológico.

A seguir, procedeu-se à sobreposição (overlay) no programa ARCGIS 9.2 dos mapas de geologia, geomorfologia e solos, que permitiu identificar as correlações espaciais e assim delimitar, em primeira aproximação, as áreas homogêneas na escala adotada, ou compartimentos morfopedológicos, do sistema hidrográfico rio dos Bois. De forma geral, os critérios utilizados para delimitar cada compartimento foram fisiográficos, cruzando-se declividade, hipsometria, solos, geomorfologia e geologia.

\section{$2^{a}$. Erodibilidade}

De acordo com Salomão (1999), a erodibilidade, aplicada aos estudos de erosão laminar, pode ser identificada com base no cruzamento do mapa das declividades e das classes de solos. Os graus de erodibilidade dos solos foram adaptados de Salomão (1999). A tabela 1 exemplifica as classes de solos e o seu respectivo grau a erodibilidade. Com o uso do programa ARCGIS 9.2 agrupou-se as classes de solos com a mesma classe, o que gerou assim o mapa de erodibilidade. 
Tabela 1 - Graus de erodibilidade (Salomão, 1999)

\begin{tabular}{|l|l|}
\hline Grau de Erodibilidade & Classes de solos \\
\hline Muito Alta & $\begin{array}{l}\text { Cambissolos, Neossolos Quartzarênicos } \\
\text { e Nitossolos }\end{array}$ \\
\hline Alta & $\begin{array}{l}\text { Argissolos (não abruptos de textura mé- } \\
\text { dia/argilosa e média) }\end{array}$ \\
\hline Média & Argissolos (de textura argilosa) \\
\hline Baixa & Latossolos \\
\hline Nula & Gleissolos \\
\hline
\end{tabular}

\section{$3^{\mathrm{a}}$. Suscetibilidade à Erosão Linear}

De acordo com Salomão (1999), a suscetibilidade à erosão possui cinco classes (tabela 2), as quais podem ser extraídas cruzando a erodibilidade com a declividade. Assim, foi possível gerar o mapa de suscetibilidade cruzando os dados dos dois mapas com o auxílio do programa ARCGIS 9.2.

Tabela 2 - Tabela das classes de suscetibilidade (Salomão, 1999).

\begin{tabular}{|l|l|l|l|l|l|}
\hline \multicolumn{2}{|c|}{} & \multicolumn{5}{|c|}{ Declividade (\%) } \\
\cline { 3 - 6 } \multicolumn{2}{|c|}{} & I $(>20)$ & II (12 a 20) & III (6 a 12) & IV $(<6)$ \\
\hline \multirow{4}{*}{ Erodibilidade } & Muito Alta & I & I & II & II \\
\cline { 2 - 6 } & Alta & I & II & II & III \\
\cline { 2 - 6 } & Média & II & III & III & IV \\
\cline { 2 - 6 } & Baixa & III & IV & IV & V \\
\cline { 2 - 6 } & Nula & Não existe & Não existe & Não existe & V \\
\hline
\end{tabular}

\section{Aspectos físicos da bacia - resultados e discussão}

\section{Geologia}

A geologia da bacia hidrográfica do rio dos Bois está representada pela associação de rochas do embasamento cristalino regional, de distintas fases orogênicas Pré-Cambrianas. A litologia é composta, principalmente, por Xisto, Anfibolito e Formação Ferrífera, ocupando 60 \% do substrato rochoso da bacia. No setor central, ocorrem corpos intrusivos Granitos Tipo Piracanjuba, do Meso a Neoproterozóico, que representam aproximadamente $15 \%$. No extremo leste da bacia, dominam as rochas metamórficas do Complexo de Ortognaisses e Ortogranulitos do MesoProterozoico, com $\sim 10 \%$ da su- 
perfície da área . Sobrepostas a estas, nos extremos norte e sul da bacia, remanescentes da cobertura detrítica-laterítica do Terciário (6\%), constituídos por latossolos e cascalhos, formam o topo da seqüência estratigráfica. No setor central da bacia, no ambiente da planície do rio dos Bois, predominam materiais aluviais do Quaternário, inconsolidados.

\section{Geomorfologia}

O relevo da bacia do rio dos Bois é caracterizado pelo predomínio de superfícies planas, remanescentes de antigas Superfícies Regionais de Aplainamento (SRA) (Latrubesse Carvalho, 2006), tanto no extremo Norte (SRA IV- $850 \mathrm{~m}$ ) como no extremo Sul, (SRA III-600 m) e de afloramentos do embasamento cristalino nos extremos leste e oeste. O setor central está representado por uma extensa área rebaixada que aloja a planície aluvial do rio dos Bois (Figura 2).

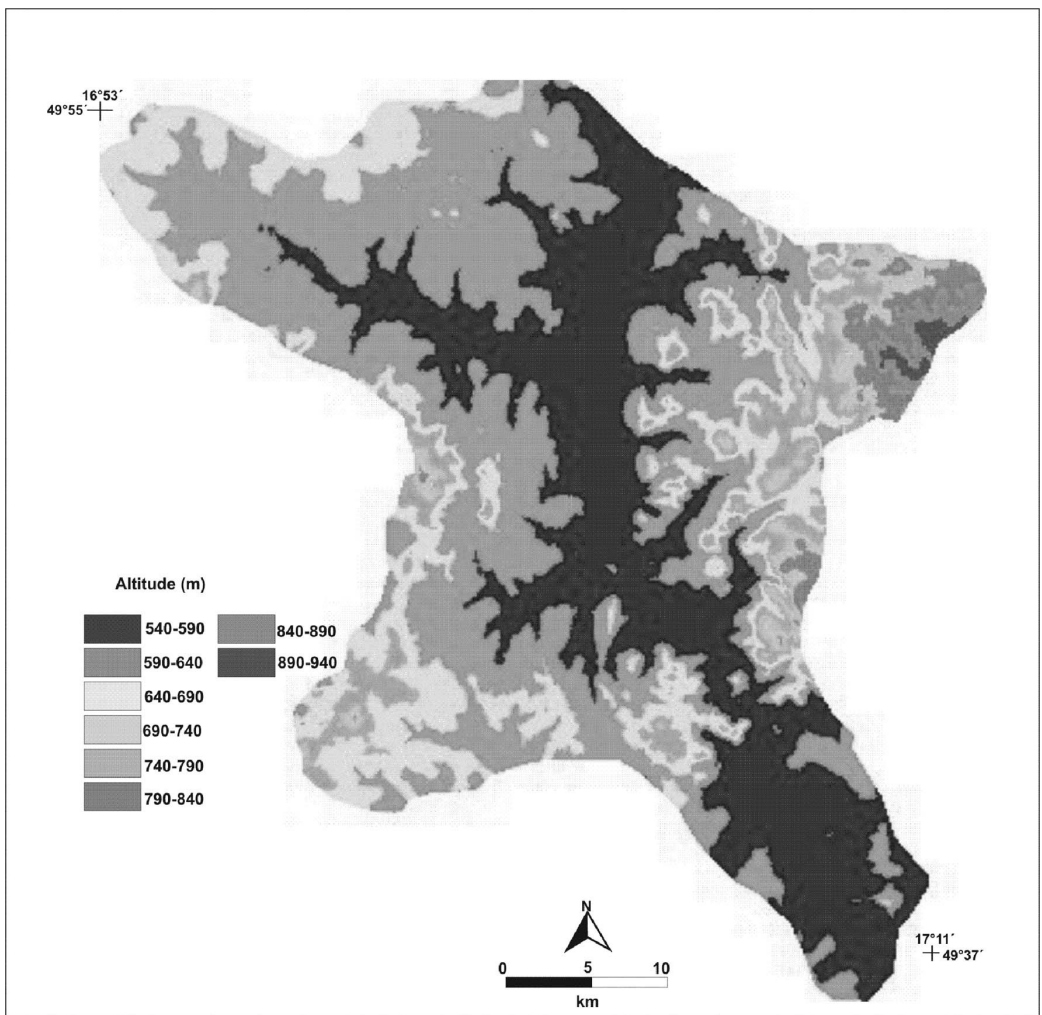

Figura 2. Mapa hipsométrico da bacia hidrográfica do rio dos Bois, GO, cotas entre 540 a 920 metros. 
O relevo plano do extremo norte e sul da bacia mostra superfícies concavizadas de pendentes suaves, com canais de baixo grau de entalhamento, em contraposição com o relevo de cuestas e "hogback"(Latrubesse e Carvalho, 2006) proeminentes no setor oriental da bacia, gerando um relevo acidentado com abruptos desníveis e encostas íngremes que representam as zonas de maior potencial natural erosivo na bacia.

Um outro aspecto importante do meio físico a ser observado é a declividade da área (Figura 3), já que esse fator é de suma importância na análise dos processos erosivos laminares, uma vez que quanto maior for a declividade, em princípio, também será maior a suscetibilidade erosiva.

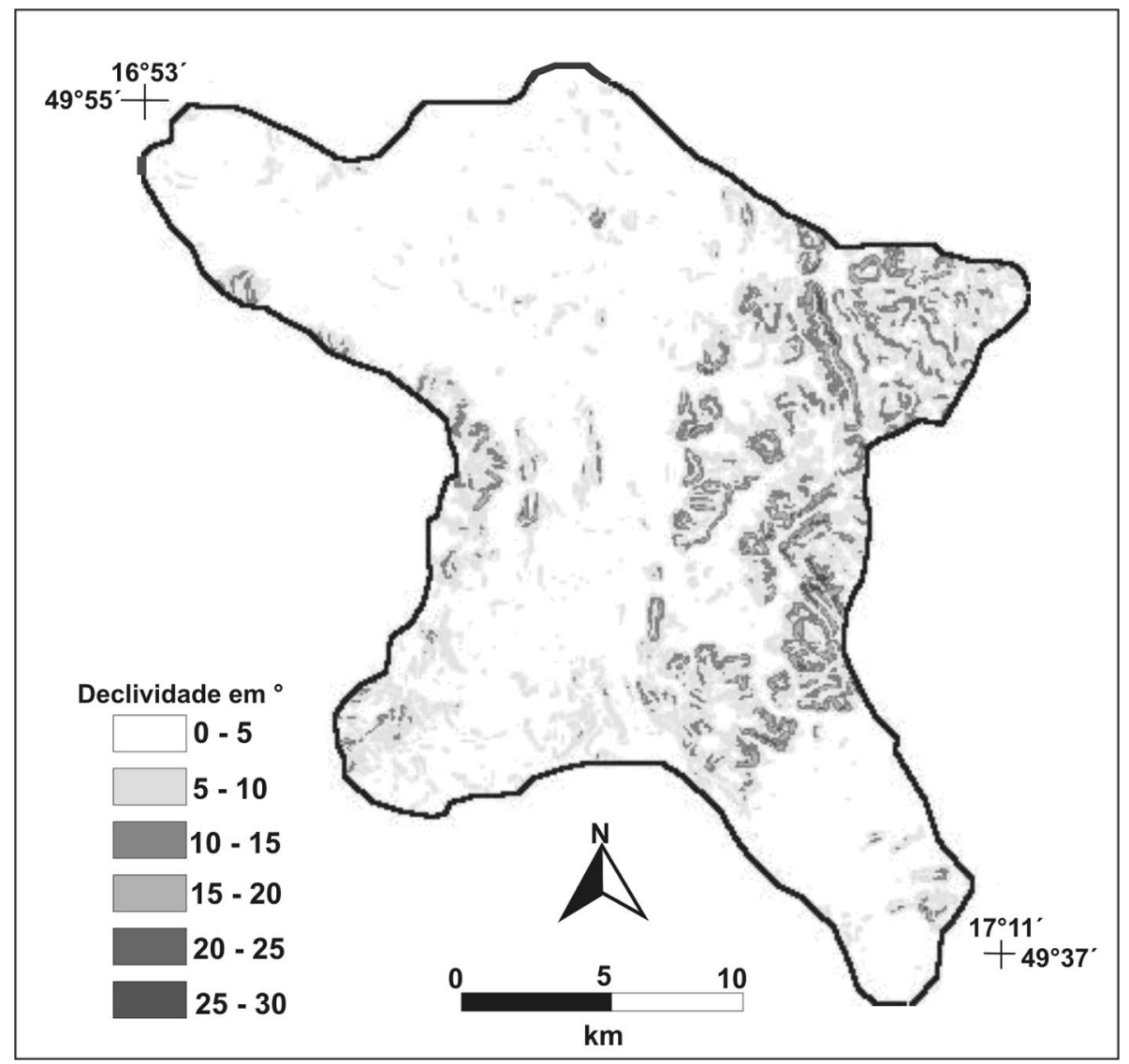

Figura 3 Mapa de declividade (graus) da bacia do rio dos Bois. 


\section{Solos}

De maneira geral, a distribuição dos solos da Bacia do rio dos Bois mostra uma sucessão lateral que varia de Latossolos Vermelhos do topo das referidas superfícies de aplainamento aos Cambissolos e Argissolos das zonas escarpadas, porém suavizadas, e por último, aos Gleissolos da planície aluvial. As figuras 4 e 5 mostram a distribuição das classes de solos e dois perfis topográficos, os quais representam a distribuição dos solos no relevo da bacia hidrográfica do rio dos Bois.

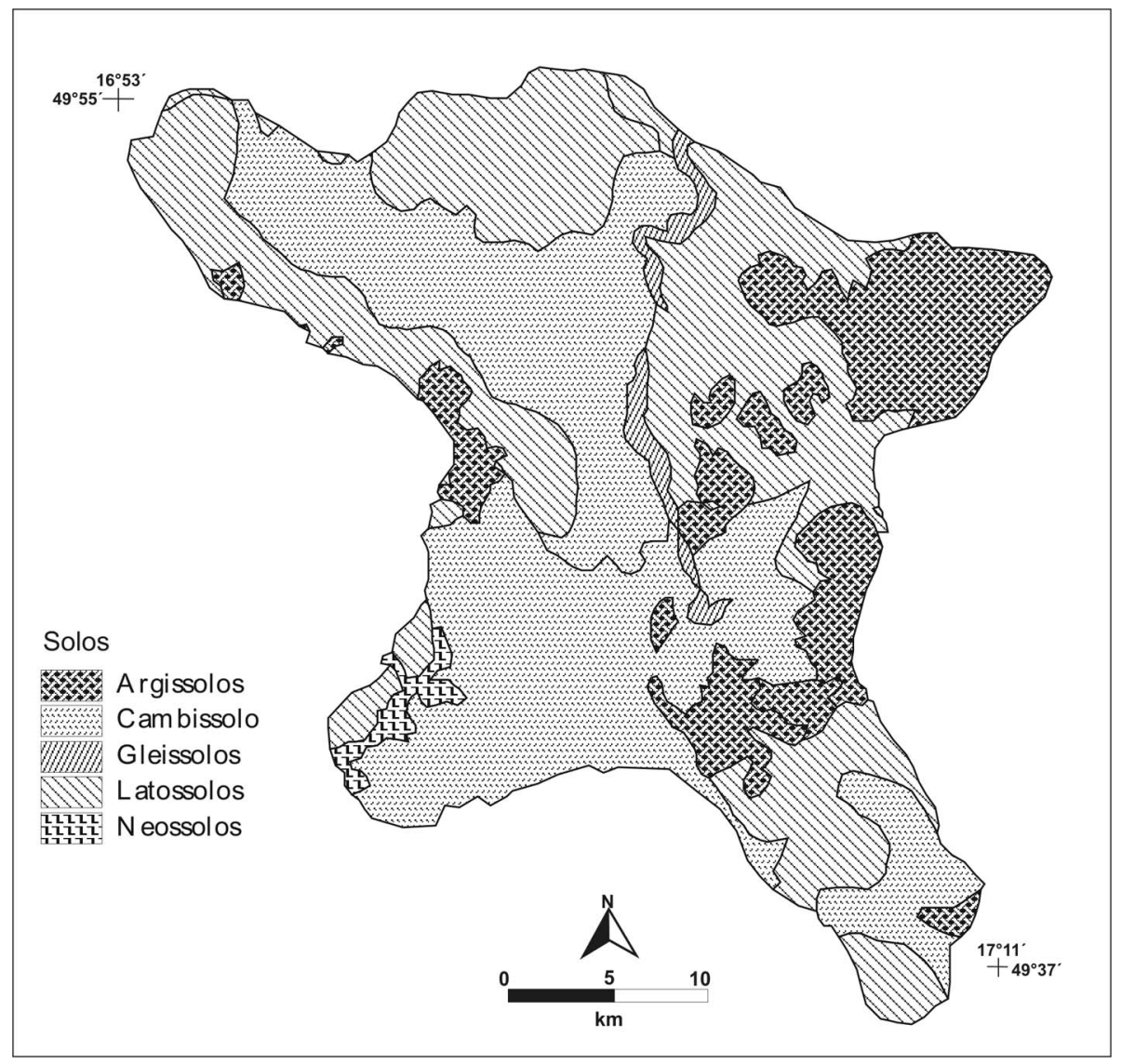

Figura 4. Mapa da distribuição dos solos na bacia do rio dos Bois $\left(1^{\circ}\right.$ nível categórico da EMBRAPA, 1999) 

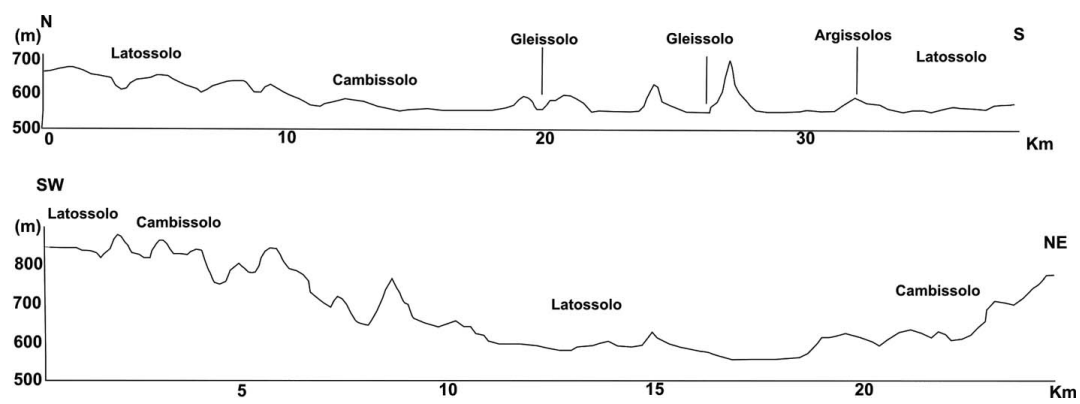

Figura 5. Perfis topográficos da bacia do rio dos Bois e os solos predominantes em nível de ordem ( $1^{\circ}$ nível categórico da Embrapa, 1999)

Assim, os Latossolos Vermelhos se associam aos declives suaves, topos regulares e contínuos, fato bastante conhecido, porém eles apresentam características distintas: os do setor norte estão associados aos Latossolos Vermelho Amarelos, compondo associação (LV+LVA) com texturas argilosa a cascalhenta sobre relevos planos; os do setor Sul apresentam textura argilosa, em relevo plano a suavemente ondulado (figura 5).

Na zona rebaixada também ocorrem elevações isoladas, com superfícies irregulares, com moderada dissecação, que apresenta também associação de Cambissolos de texturas argilosa a cascalhenta e Argissolos de texturas média, cascalhenta a argilosa. Nas elevações isoladas (feições residuais) dessa zona ocorrem Neossolos litólicos.

\section{Suscetibilidade à erosão}

Com base na correlação espacial da erodibilidade e declividade é possível se chegar a uma definição das classes de suscetibilidade à erosão laminar e expressá-las num mapa, a partir de delimitações de áreas homogêneas quanto a essa característica, como mostra a figura 7.

Observando-se o mapa de solos (figura 4) e o de erodibilidade (figura 6), pode-se constatar que os Latossolos e os Gleissolos possuem uma baixa ou nula erodibilidade, respectivamente, seguindo-se a associação de Cambissolos/Argissolos e Neossolos litólicos, com média erodibilidade e, por fim, o Argissolo de textura cascalhenta associado aos Neossolos litólicos que apresentam os maiores valores de erodibilidade (tabela 3). 
A figura 7 mostra a distribuição das classes de suscetibilidade à erosão laminar da área.

Tabela 3 - Classes de erodibilidade por classes de solos existentes na bacia hidrográfica do rio dos Bois,GO.

\begin{tabular}{|l|l|}
\hline Classes de Erodibilidade & Unidades Pedológicas \\
\hline 1. Muito Alta & $\begin{array}{l}\text { Neossolos Litolicos- Argissolos com textura cas- } \\
\text { calhenta - Cambissolo }\end{array}$ \\
\hline 2. Alta & $\begin{array}{l}\text { Argissolos- ( abruptos de textura média/argilosa e } \\
\text { média)-Neossolos litólicos }\end{array}$ \\
\hline 3. Média & Cambissolos- Argissolos (de textura argilosa) \\
\hline 4.Baixa & Latossolos \\
\hline 5. Nula & Gleissolos \\
\hline
\end{tabular}

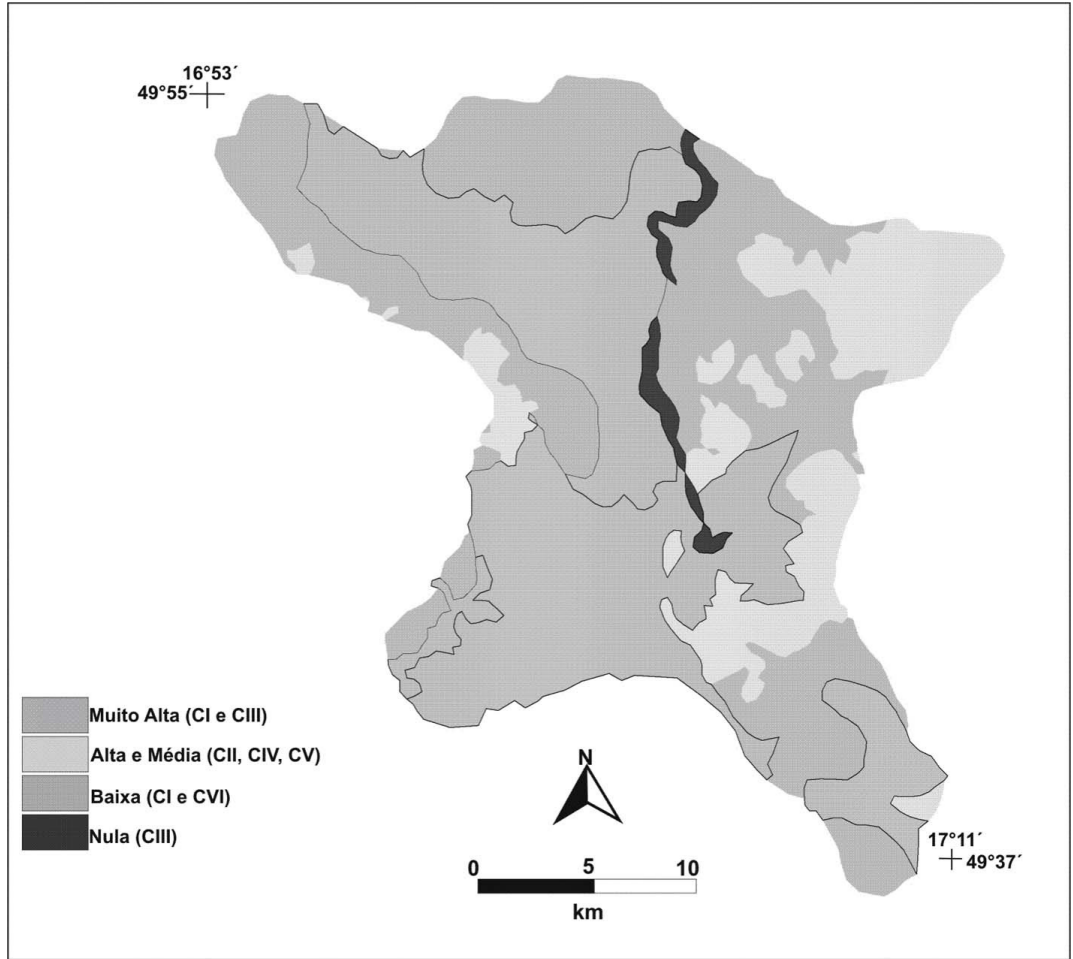

Figura 6. Mapa de erodibilidade dos solos da bacia do rio dos Bois, GO. 


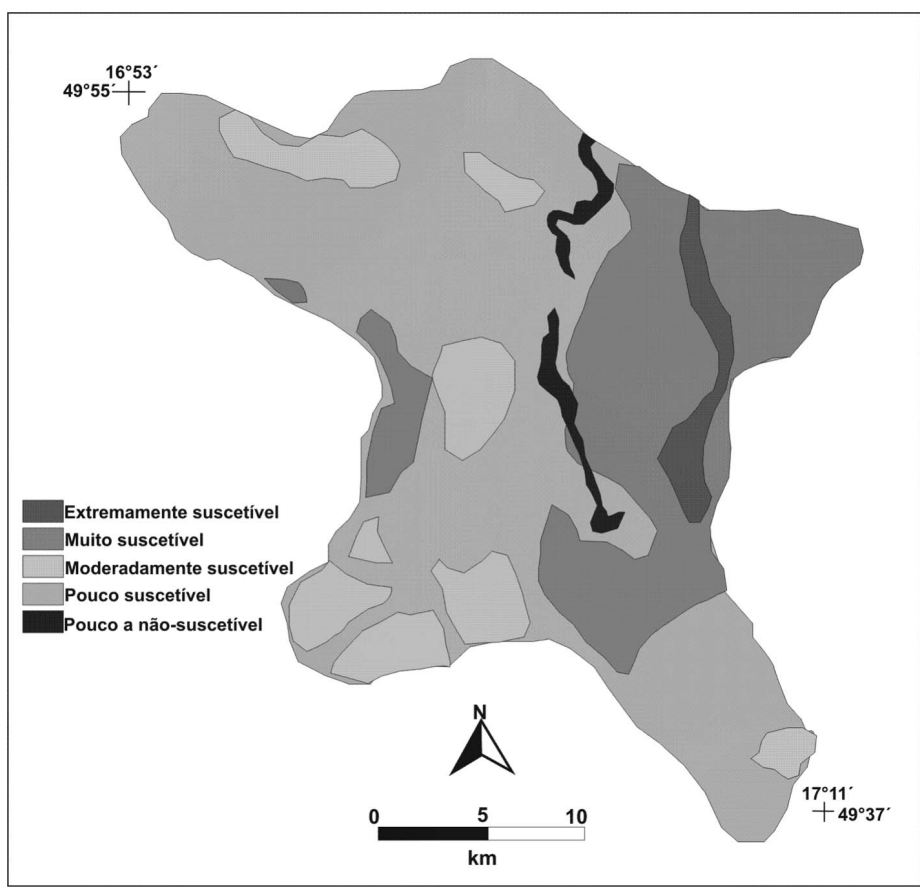

Figura 7. Mapa de Suscetibilidade a erosão laminar, bacia hidrográfica do rio dos Bois, GO.

O mapa de suscetibilidade (figura 7) permite perceber que a maior parte da área da bacia se apresenta na classe de suscetibilidade III (moderadamente suscetível), em que os terrenos apresentam problemas de conservação devido, sobretudo, ao tipo de solo, que são os Cambissolos e Argissolos associados aos Neossolos litólicos e a um relevo irregular de declives acentuados. Sendo assim, são mais indicados para pastagens e culturas perenes, e eventualmente, culturas anuais, desde que utilizadas práticas intensivas e mecânicas de controle da erosão. Na zona deprimida há predominância de relevos movimentados, com formas de dissecação ativas, o que corrobora e explica a moderada suscetibilidade à erosão laminar nessa área.

As classes V (pouco a não suscetível) e IV (pouco suscetível) são aquelas que apresentam uma declividade baixa, de 0 a $3^{\circ}$ e de 3 a $6^{\circ}$, localizadas nos remanescentes das superfícies de aplainamento regional, que caracterizam os setores extremo nordeste e sul da bacia, condicionando uma menor suscetibilidade à erosão laminar, favorecida também pela presença dos Latossolos Vermelhos e Vermelho-Amarelos, que são solos que apresentam baixa erodibilidade. 
Solos com média erodibilidade e com declividades baixas (sobretudo até $6^{\circ}$ ) correspondem à zona rebaixada que se situa entre as bordas escarpadas da bacia e a planície aluvial do rio dos Bois.

No setor superior da zona rebaixada central, ocupando encostas dos extremos oeste e leste da bacia, tem-se a classe II (muito suscetível), ocupando uma área, que apresenta uma declividade maior, de 6 a $12^{\circ}$ ou mais, também com presença de Argissolos e Neossolos litólicos. Essa classe apresenta problemas complexos de conservação, sendo mais apropriadas para reflorestamento e parcialmente favoráveis à ocupação por pastagens. Isso se deve tanto ao fato dos solos não serem aptos para agricultura, como também pela declividade ser um pouco maior que na classe anterior.

Por último, a classe I (extremamente suscetível), ocupa pequena faixa da área de estudo e corresponde aos locais onde a declividade é maior (de 20 a $45^{\circ}$ ), que corresponde à faixa escarpada que limita a bacia, o que explica sua alta suscetibilidade erosiva, devido à sua elevada declividade. Áreas indicadas para preservação ou reflorestamento, fato inclusive garantido pelas leis ambientais.

\section{Uso e ocupaçâo dos solos}

O mapa de ocupação e uso dos solos da bacia mostra uma predominância do uso por pastagem (58,58\%), sobre Cambissolos e Argissolos (Tabela 4 e figura 8 ).

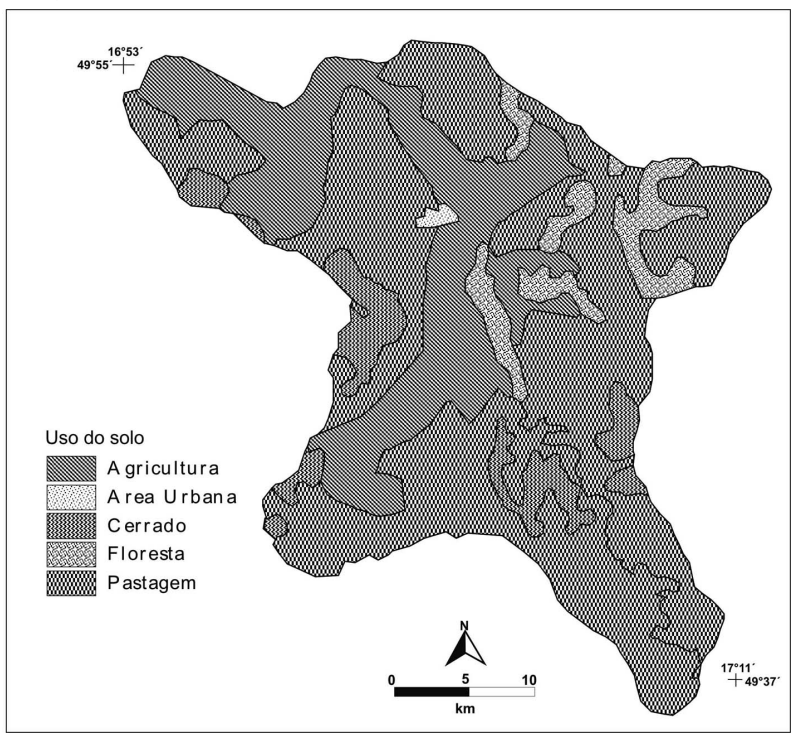

Figura 8. Mapa de Uso do solo na bacia do rio dos Bois. 
Tabela 4- Uso e ocupação por classes de solo na Bacia do Rio dos Bois

\begin{tabular}{|c|c|c|c|c|}
\hline USO & SOLO & AREA & \% ÁREA & \%TOTAL \\
\hline \multirow{6}{*}{ Agricultura } & Argissolos & 1,651 & $1,05 \%$ & \multirow{6}{*}{$26,30 \%$} \\
\hline & Cambissolos & 85,507 & $54,19 \%$ & \\
\hline & Gleissolos & 2,153 & $1,36 \%$ & \\
\hline & Latossolos & 65,868 & $41,74 \%$ & \\
\hline & Neossolos & 2,621 & $1,66 \%$ & \\
\hline & TOTAL & \multicolumn{2}{|l|}{157,8} & \\
\hline \multirow{6}{*}{ Pastagem } & Argissolos & 56,453 & $16,20 \%$ & \multirow{6}{*}{$58,08 \%$} \\
\hline & Cambissolos & 154,928 & $44,46 \%$ & \\
\hline & Gleissolos & 1,864 & $0,53 \%$ & \\
\hline & Latossolos & 132,405 & $37,99 \%$ & \\
\hline & Neossolos & 2,824 & $0,81 \%$ & \\
\hline & TOTAL & \multicolumn{2}{|l|}{348,474} & \\
\hline \multirow{5}{*}{ Cerrado } & Argissolos & 25,648 & $56,25 \%$ & \multirow{5}{*}{$7,60 \%$} \\
\hline & Cambissolos & 5,866 & $12,86 \%$ & \\
\hline & Latossolos & 12,516 & $27,45 \%$ & \\
\hline & Neossolos & 1,558 & $3,42 \%$ & \\
\hline & TOTAL & \multicolumn{2}{|l|}{45,588} & \\
\hline \multirow{3}{*}{ Floresta } & Argissolos & 19,61 & $50,40 \%$ & \multirow{3}{*}{$4,62 \%$} \\
\hline & Latossolos & 8,116 & $25,79 \%$ & \\
\hline & TOTAL & \multicolumn{2}{|l|}{27,726} & \\
\hline \multirow{5}{*}{ Floresta Aluvial } & Argissolos & 0,851 & $6,60 \%$ & \multirow{5}{*}{$2,15 \%$} \\
\hline & Cambissolos & 2,448 & $18,98 \%$ & \\
\hline & Gleissolos & 7,24 & $56,12 \%$ & \\
\hline & Latossolos & 2,355 & $18,26 \%$ & \\
\hline & TOTAL & \multicolumn{2}{|l|}{12,894} & \\
\hline
\end{tabular}

Pela figura 8 e tabela 4, correlacionados ao mapa de solos (figura 4) pode-se constatar que as culturais anuais estão associadas aos setores elevados e com topos planos dos remanescentes das superfícies regionais de aplainamento (SRA).

Os setores com topografia mais irregular, das encostas íngremes com fortes declives e também como a planície, se apresentam cobertos com Florestas, Estacionais (Decidual/submontana) e com potencialidade de uso muito limitado a pastagens, devendo ser destinados a áreas de preservação 
permanente ou similar,sendo conveniente ressaltar que apenas pouco mais de 14\% da área estaria protegido pela cobertura vegetal (tabela 4), estando os demais setores com (cerca de $80 \%$ ) com usos que podem ou não estar em conflitos, como se verá adiante.

A participação econômica da bacia do rio dos Bois para os municípios em que ela está inserida é fundamental, pois no último censo agropecuário (IBGE, 2006), o uso das terras nos principais municípios onde a bacia está inserida, Cezarina, Varjão e Palmeiras de Goiás, como apresentado na tabela 5, está em uma conformidade com as capacidades de uso das terras.

Tabela 5 - Uso das terras nos municípios onde está inserida a Bacia do Rio dos Bois. Fonte: IBGE. (2006)

\begin{tabular}{|l|l|l|l|}
\hline Município & Lavouras & Pastagens & Matas e florestas \\
\hline Cezarina & $5,10 \%$ & $61,70 \%$ & $12,78 \%$ \\
\hline Palmeiras de Goiás & $12,49 \%$ & $60,17 \%$ & $13,39 \%$ \\
\hline Varjão & $1,63 \%$ & $35,20 \%$ & $9,79 \%$ \\
\hline
\end{tabular}

\section{Compartimentação morfopedológica}

A figura 9, a seguir, apresenta os 6 compartimentos morfopedológicos delimitados na bacia estudada, indicados em algarismo romano (CI a CIV).

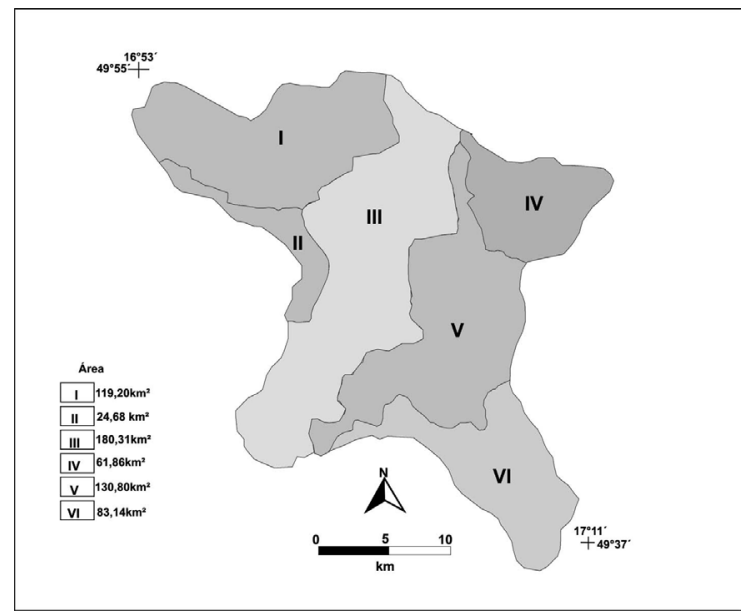

Figura 9. Mapa de Compartimentos morfopedológicos da bacia do rio dos Bois. 
A seguir são apresentados as características de cada compartimento morfopedológico.

O compartimento I (C-I), situado no extremo NNW da bacia hidrográfica, ocupa uma área de 119,39 $\mathrm{km}^{2}$ e caracteriza uma parte mais elevada e plana. Predominam os Latossolos (60,34\%) e os Cambissolos $(39,66 \%)$. A quase totalidade do solo está ocupada com pastagem $(48,12 \%)$ e agricultura (50,96\%). Observamos que a área ainda preservada com cerrado atinge menos de $1 \%$ do compartimento, o que é preocupante do ponto de vista ambiental, pois mostra que nem mesmo a legislação, que prevê $20 \%$ de reserva legal, está sendo cumprida.

Compartimento II (CII), situado numa faixa a oeste da bacia, ocupa uma área muito pequena, de $27,24 \mathrm{~km}^{2}$, com relevo muito irregular (541 a $848 \mathrm{~m}$ ) onde predominam os Latossolos (57,73\%) e os Argissolos $(36,2 \%)$. Nos Latossolos predomina o uso com pastagens (46,75\%), e uma boa parte deles está ocupada com cerrado $(36,75 \%)$. A pequena participação da agricultura $(19,5 \%)$ está diretamente relacionada ao relevo do compartimento, o que também explica o fato de a quase a totalidade dos Argissolos estar com a vegetação de cerrado preservada, contribuindo para que o compartimento tenha $55,44 \%$ do seu solo ocupado com esta vegetação natural.

O compartimento III (CIII), que cruza diagonalmente a bacia no sentido noroeste-nordeste, ocupa uma área de $178,67 \mathrm{~km}^{2}$. Os solos predominantes são os Cambissolos (64,2\%), ocupados quase que na mesma proporção por agricultura e pastagem. Os Latossolos $(27,22 \%)$, têm a predominância de pastagem $(45,85 \%)$. A presença de Gleissolos (háplicos distróficos) (4,69\%) no fundo de vale, quase que totalmente ocupado por floresta aluvial é um diferencial neste compartimento pela preservação de mata ciliar e de galeria que a compõem. Esses Gleissolos compreendem a classe de solos hidromórficos constituídos por material mineral, que apresentam um horizonte glei dentro dos primeiros $50 \mathrm{~cm}$ da superfície do solo, ou a profundidades entre 50 e $125 \mathrm{~cm}$ desde que imediatamente abaixo de horizontes A ou E. Esses solos são permanente ou periodicamente saturados por água. A água de saturação ou permanece estagnada internamente, ou a saturação ocorre por fluxo lateral lento no solo (EMBRAPA, 1999). São solos problemáticos em termos de uso agropecuário devido atividade bioquímica de ambiente redutor em ambiente encharcado e, com freqüência indicados como área de preservação permanente. 
O compartimento IV (CIV), se situa no extremo nordeste da bacia, possui área de $60,2 \mathrm{~km}^{2}$, e é onde predominam os Argissolos $(75,13 \%)$ ocupados com pastagem (75,77\%) e floresta (34,06\%). Os Latossolos $(24,81 \%)$, na grande maioria ocupados por pastagem nas partes ligeiramente mais acidentadas, estão ainda cobertos em boa parte com florestas (34,06\%). É o compartimento mais elevado da bacia, o que talvez explique a preservação de parte notável da sua vegetação natural $(31,25 \%)$.

A ocorrência de Cambissolos e Neossolos litolicos, corresponde aos tipos predominantes de solos nos Compartimentos III e V, apresentando elevados índices de erodibilidade (Ribeiro e Salomão, 2003)

O compartimento $\mathbf{V}(\mathbf{C V})$ se situa no centro-leste da bacia, com área de $128,32 \mathrm{~km}^{2}$, relevo bastante irregular, onde predominam os Cambissolos $(40,77 \%)$ quase que exclusivamente ocupados por pastagem. Estão presentes também os Latossolos (25,27\%) e os Argissolos (31,66\%). Nos fundos de vale tem-se a presença de Gleissolos, (2,25\%) ocupados, em sua maior parte, por floresta aluvial.

O compartimento VI (CVI) se situa no extremo sudeste da bacia, com uma área de $83,43 \mathrm{~km}^{2}$, de relevo plano, com a presença de Cambissolos (42,85\%), Latossolos (45,91\%) e Argissolos $(11,02 \%)$ e tem sua área quase que totalmente ocupada por pastagem $(94,6)$, com uma pequena área preservada com cerrado $(5,4 \%)$.

\section{Conclusões}

Analisando o quadro síntese (quadro 1) abaixo, podemos concluir que em muitas áreas da bacia, nos compartimentos CI, CIII e CIV, são necessários cuidados especiais no uso e ocupação dos solos. Nos compartimentos CI e CIII, onde é grande a presença de Cambissolos, ocupados com agricultura temporária, é necessário uma readequação no uso destes solos, com a substituição da agricultura por pastagem ou até mesmo com culturas permanentes, como reflorestamento. Já no compartimento CIV, onde é grande a presença dos Argissolos ocupados com pastagem, seria importante utilizar medidas de prevenção a erosões laminares, como o reflorestamento para preservação da área. 
Quadro 1 - Quadro-síntese das características dos compartimentos

\begin{tabular}{|c|c|c|c|c|c|}
\hline 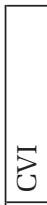 & $\begin{array}{l}\mathscr{P} \\
\mathbb{1} \\
\infty \\
\infty\end{array}$ & 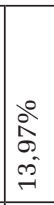 & 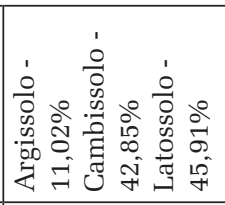 & 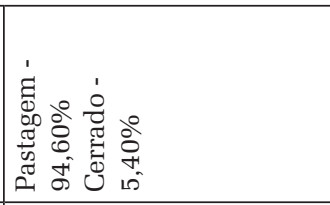 & 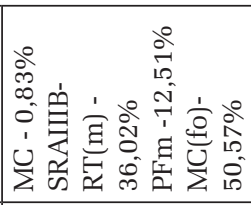 \\
\hline 己 & 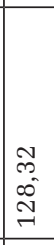 & $\begin{array}{l}0 \\
\infty \\
o \\
o \\
\vec{N} \\
-1\end{array}$ & 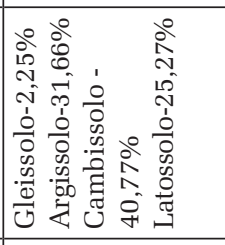 & 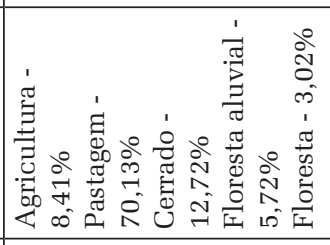 & 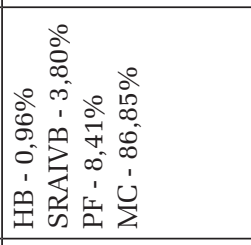 \\
\hline 光 & $\begin{array}{l}\text { जे } \\
\text { ô } \\
\text { ¿े }\end{array}$ & $\begin{array}{l}0 \\
0^{2} \\
0 \\
0 \\
0\end{array}$ & 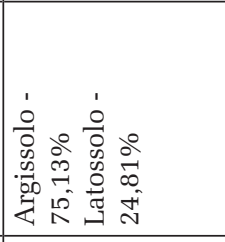 & 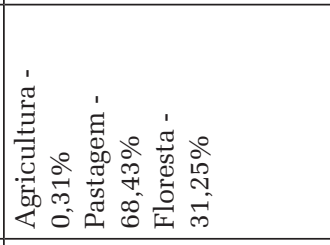 & 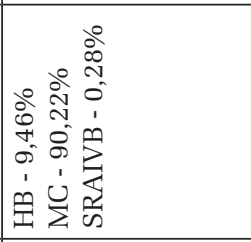 \\
\hline 보 & $\begin{array}{l}\hat{0} \\
0 \\
\stackrel{\infty}{\circ} \\
\stackrel{-}{-}\end{array}$ & 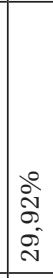 & 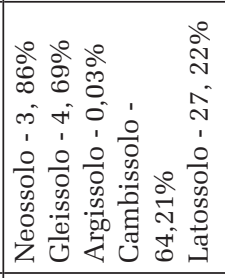 & 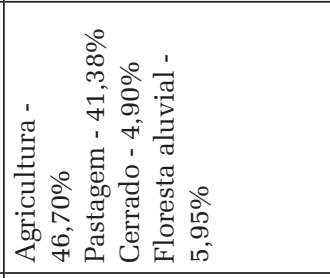 & 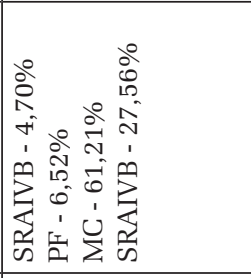 \\
\hline 붕 & \begin{tabular}{l}
\multirow{N}{N}{} \\
N
\end{tabular} & $\begin{array}{l}80 \\
60 \\
10 \\
+1\end{array}$ & 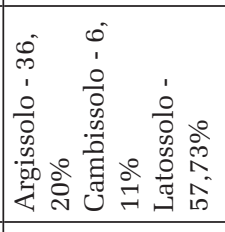 & 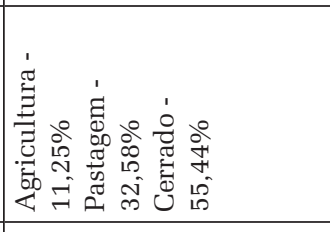 & 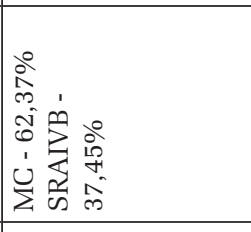 \\
\hline U & 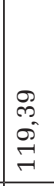 & $\begin{array}{l}\text { ठे } \\
\text { ठे } \\
\text { बे }\end{array}$ & 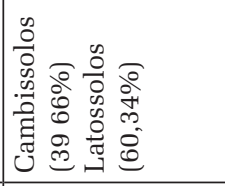 & 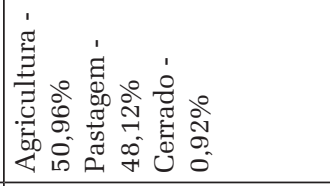 & 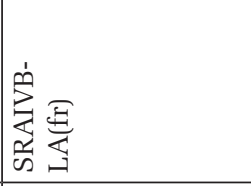 \\
\hline 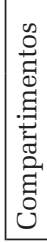 & & 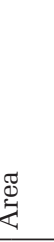 & $\begin{array}{l}\infty \\
0 \\
0 \\
\infty\end{array}$ & $\begin{array}{l}0 \\
0 \\
0 \\
0 \\
0 \\
0 \\
0 \\
0\end{array}$ & 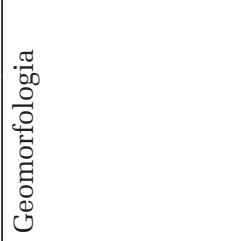 \\
\hline
\end{tabular}




\begin{tabular}{|c|c|c|c|c|c|}
\hline 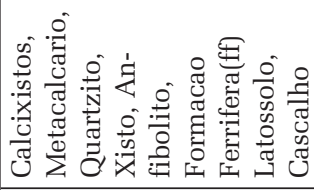 & 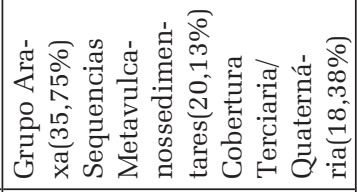 & . & 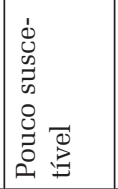 & 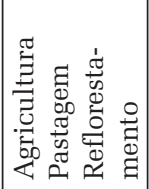 & $\frac{0}{3}$ \\
\hline 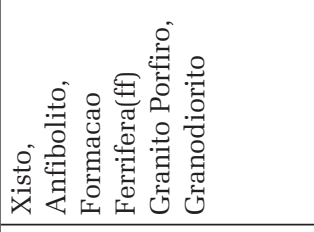 & 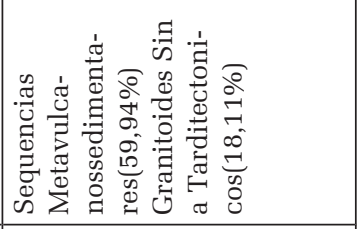 & 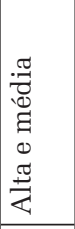 & 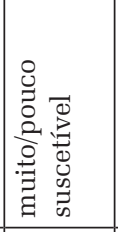 & 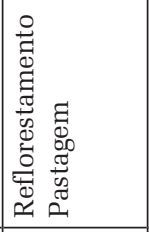 & $\begin{array}{l}\text { 을 } \\
\text { z }\end{array}$ \\
\hline 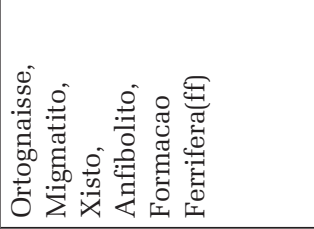 & 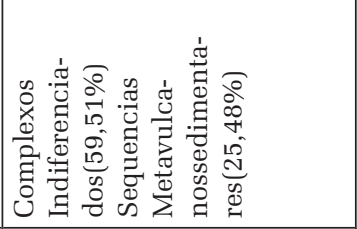 & 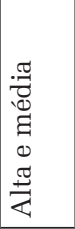 & 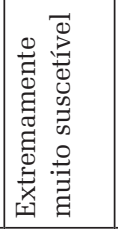 & 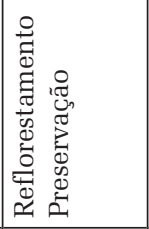 & 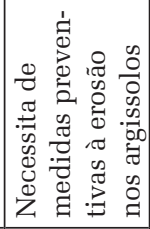 \\
\hline 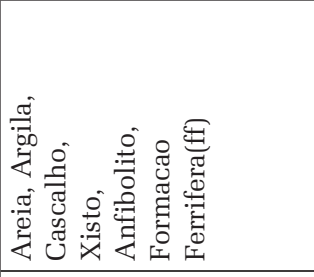 & 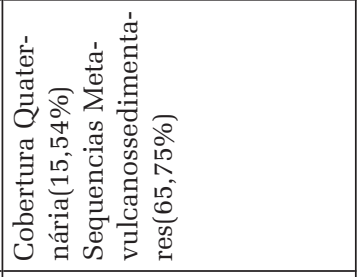 & 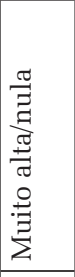 & 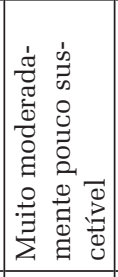 & 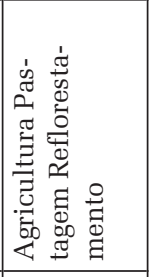 & 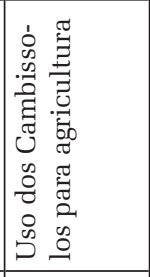 \\
\hline 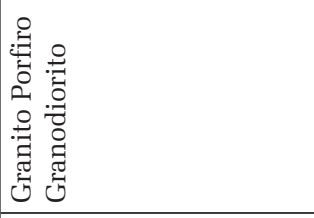 & 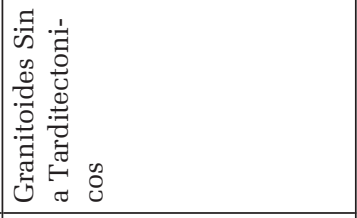 & 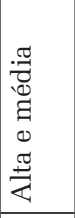 & 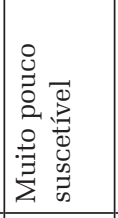 & 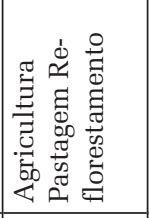 & 울 \\
\hline 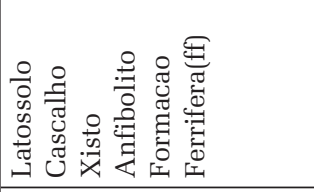 & 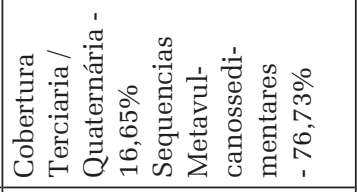 & 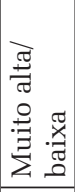 & 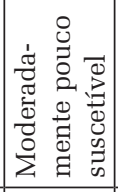 & 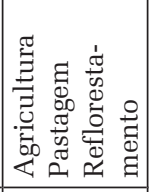 & 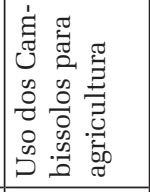 \\
\hline$\stackrel{\substack{0 \\
0}}{\frac{0}{0}}$ & 芯 & \multirow[b]{2}{*}{ 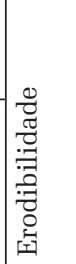 } & \multirow{2}{*}{ 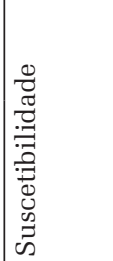 } & \multirow{2}{*}{ 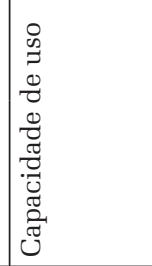 } & \multirow[b]{2}{*}{ 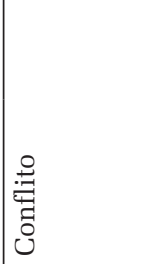 } \\
\hline & 0 & & & & \\
\hline
\end{tabular}


O estudo detalhado do meio físico de uma determinada bacia hidrográfica auxilia no planejamento de uso e ocupação das terras, com o conseqüente melhor aproveitamento dos seus solos, promovendo a diminuição da ocorrência de degradação ambiental provocada pelo uso e manejo inadequados das terras. Assim, o estudo da compartimentação morfopedológica e da suscetibilidade à erosão laminar da bacia do rio dos Bois forneceu subsídios que podem contribuir não só para um diagnóstico mais completo sobre a problemática erosiva da área, bem como para verificar se há coincidência ou não entre os setores mais críticos quanto à erosão laminar, de modo a entender a origem e a dinâmica desses processos e, conseqüentemente validar as ações de controle, sobretudo preventivas, já que a bacia não apresenta graus elevados de conflito entre a capacidade do uso das classes e o uso atual dos solos.

Uma vez que o mapa de suscetibilidade reflete apenas as condições naturais dos terrenos frente ao desenvolvimento dos processos erosivos e, sabendo que "áreas com um mesmo nível de suscetibilidade ocupadas de maneira diferente apresentam variados potenciais ao desenvolvimento da erosão laminar" (SALOMÃO, 1999), o mapa de risco (ou potencial) à erosão laminar pode ser definido como o resultado da interação entre a suscetibilidade de uma área e o seu uso e ocupação atual. Nesse sentido, 3 compartimentos se revelaram de maior risco à instalação de processos erosivos (CI; CIII; e CIV) em todos devido à prática agrícola em solos sem capacidade de uso para o uso desse tipo, em especial Cambissolos (CI e CIII) e Argissolos (CIV), estes onde o uso pode ser o mesmo (pastagem) mas com manejo adequado para controle preventivo da erosão.

Por fim, a metodologia revelou-se rápida e eficiente para um diagnóstico inicial da bacia estudada, porém sugere-se estudos mais detalhados dos compartimentos que se revelaram de maior risco.

1. Este artigo é resultado de pesquisa realizada na disciplina de Solos e Meio Ambiente ministrada pela professora $\mathrm{Dr}^{\mathrm{a}}$ : Selma Simões de Castro.

\section{Referências}

BARBALHO, M. G. S. Morfopedologia aplicada ao diagnóstico e diretrizes para o controle dos processos erosivos lineares na alta bacia do rio Araguaia (GO/MT). Dissertação de Mestrado apresentada ao Programa de Pesquisa e Pós-Graduação em Geografia da Universidade Federal de Goiás, Goiânia, 2002. 
CARVALHO, T. M.; LATRUBESSE, E.. O uso de modelos digitais do terreno (MDT) em análises macrogeomorfológicas: o casa da bacia hidrográfica do Araguaia. Revista Brasileira de Geomorfologia, 5(1):85-93p. 2004

CARVALHO, Thiago Morato; LAHM, R. Alexandre.; RAMÍREZ, Rina.; THOMÉ, José. Modelagem digital na análise espacial de moluscos terrestres em Lima, Perú. In: Simpósio Brasileiro de Sensoriamento Remoto (SBSR), 11., Belo Horizonte. São José dos Campos: INPE. Anais, 1277-1279p. 2003b

CARVALHO, T.M. Uso de modelos digitais do terreno (MDT) para analises geomorfológicas e geológicas: o caso de estudo da bacia hidrográfica do rio Araguaia. Monografia (Geografia) Pontifícia Universidade Católica do Rio Grande do Sul, Porto Alegre, RS. 108p.2003a

CASTRO, S.S. \& SALOMÃO, F.X.T. Compartimentação Morfopedológica: considerações metodológicas. GEOUSP Nº 7, p.29-35, São Paulo. 2000.

LATRUBESSE, E.M.; CARVALHO, T.M. 2006. Geomorfologia do Estado de Goiás e Distrito Federal. Goiânia, Superintendencia de Geologia e Mineração.

LEPSCH, I. F. Formação e conservação dos solos. São Paulo: Oficina de Textos. 2002. p.147177.

LEPSCH, I et al. Manual para o Levantamento do Meio Físico de Classificação das Terras no Sistema de Capacidade de Uso. Campinas: Soc. Bras. de Ciência do Solo. 1991.

RIBEIRO, Joaquim Corrêa; SALOMÃO, Fernando Ximenes de Tavares. Abordagem Morfopedológica Aplicada ao Diagnóstico e Prevenção de Processos Erosivos na Bacia Hidrográfica do Alto Rio da Casca, MT. São Paulo, UNESP, Geociências, v. 22, n. 1, p. 83-95, 2003.

SALOMÃO, Fernando Ximenes de Tavares. Controle e prevenção dos processos erosivos. In: GUERRA, T. A. J.; SILVA, A.S. \& BOTELHO, R. G. (Organizadores). Erosão e Conservação dos solos: conceitos, temas e aplicações. Rio de Janeiro: Bertrand Brasil, 1999.

Fernando Pereira dos Santos - Doutorando do CIAMB/UFG - Professor do CEPAE/UFG

Maximiliano Bayer - Doutorando do CIAMB/UFG - Professor do IESA/UFG

Thiago Morato de Carvalho - Doutorando do CIAMB/UFG - Pesquisador colaborador do LABOGEF/UFG 
